\title{
Risk factors for nonocclusive mesenteric ischemia after elective cardiac surgery
}

\author{
Heinrich Volker Groesdonk, MD, ${ }^{\text {a,b }}$ Matthias Klingele, MD, ${ }^{\mathrm{c}}$ Sandra Schlempp, MS, ${ }^{\mathrm{a}}$ \\ Hagen Bomberg, MD, ${ }^{a}$ Wolfram Schmied, Dipl Psych, ${ }^{\mathrm{a}}$ Peter Minko, MD, ${ }^{\mathrm{d}}$ and \\ Hans-Joachim Schäfers, MD ${ }^{\mathrm{a}}$
}

\begin{abstract}
Objective: Nonocclusive mesenteric ischemia (NOMI) may occur after cardiopulmonary bypass. It is crucial to early identify patients who are at risk of developing this complication. The aim of this prospective study was to evaluate perioperative risk factors in a large cohort of patients undergoing elective cardiac surgery.
\end{abstract}

\begin{abstract}
Methods: From January 1, 2010, to March 31, 2011, all patients scheduled for elective cardiac surgery were screened for participation in this trial. If NOMI was suspected, arterial angiography was performed. NOMI and non-NOMI patients were compared with respect to all variables assessed in this study. Additionally, odds ratios were calculated. Linear discriminant analyses as well as logistic regression analyses were performed to develop a model that identifies patients at risk for developing NOMI.

Results: Eight hundred sixty-five patients were included in the study, of whom 78 developed NOMI. Among preoperative parameters, renal insufficiency, diuretic therapy, and age $>70$ years showed the highest odds ratios for postoperative NOMI. The highest odds ratios for development of NOMI were observed with postoperative variables. In particular, the need for intra-aortic balloon pump support and serum lactate concentrations $>5$ $\mathrm{mmol} / \mathrm{L}$ proved to be serious risk factors. Using a linear discriminant analysis with 7 variables, $92.3 \%$ of patients were correctly classified (sensitivity $76.9 \%$, specificity $93.8 \%$ ).
\end{abstract}

Conclusions: A high index of suspicion for NOMI in patients with the above-mentioned risk factors may decrease the diagnostic and therapeutic delay. To identify at-risk patients the developed risk equation is a useful tool with a high specificity. (J Thorac Cardiovasc Surg 2013;145:1603-10)

Non-occlusive mesenteric ischemia (NOMI) is a rare but serious complication after cardiac surgery. NOMI was first described by Ende in $1958^{1}$ as summarizing all forms of mesenteric ischemia without occlusion of the mesenteric arteries. NOMI has been generally defined as "intestinal gangrene in the presence of a patent arterial tree." Although incidence rates around $1 \%$ have been reported, mortality is up to $90 \%{ }^{3,4}$

The exact pathophysiology of NOMI is currently not fully understood; it is assumed that the key mechanism is an extreme reduction or maldistribution of splanchnic blood flow. Intestinal ischemia results in compromised integrity of the mucosal layer with bacterial translocation, bacteremia, and the development of multiorgan failure. ${ }^{3}$

\footnotetext{
From the Department of Thoracic and Cardiovascular Surgery, ${ }^{a}$ Department of Anesthesiology, Intensive Care Medicine and Pain Medicine, ${ }^{\mathrm{b}}$ Department of Medicine, Division of Nephrology and Hypertension, ${ }^{c}$ and Department of Diagnostic and Interventional Radiology, ${ }^{\mathrm{d}}$ Saarland University Medical Center, Homburg/Saar, Germany.

Disclosures: Authors have nothing to disclose with regard to commercial support.

Received for publication May 7, 2012; revisions received Oct 6, 2012; accepted for publication Nov 6, 2012; available ahead of print Dec 10, 2012.

Address for reprints: Hans-Joachim Schäfers, MD, Department of Thoracic and Cardiovascular Surgery, University Medical Center, University of Saarland, Kirrbergerstraße 66421, Homburg/Saar, Germany (E-mail: h-j.schaefers@uks.eu). $0022-5223 / \$ 36.00$

Copyright (C) 2013 by The American Association for Thoracic Surgery

http://dx.doi.org/10.1016/j.jtcvs.2012.11.022
}

The clinical signs of NOMI-oliguria, increased serum lactate levels, decreased oxygenation, or hypotensionare unspecific. The same is true for abdominal pain, which in addition may be suppressed by analgosedation. ${ }^{5,6}$

Angiography is currently the only means of establishing the diagnosis; in addition it allows for intra-arterial application of vasodilators as the specific treatment. Angiography, however, is an invasive procedure that cannot be applied too liberally. In addition, it must be instituted early enough to be able to correct the vascular pathology. To minimize morbidity and mortality due to NOMI, it is thus crucial to identify patients who are at risk of developing this complication. ${ }^{7}$

A variety of risk factors have been proposed on the basis of retrospective investigations of heterogeneous patient cohorts. Among others, advanced age, renal failure, and different forms of shock as well as the use of an intra-aortic balloon pump (IABP) have been found to be associated with NOMI. ${ }^{3,4,7}$ At this time there is no prospective identification of risk factors for NOMI.

Therefore, aim of this prospective study was to identify perioperative risk factors for NOMI in a large cohort of patients undergoing elective cardiac surgery.

\section{METHODS}

The study was designed as a prospective cohort study and approved by the local ethics committee (Landesärztekammer des Saarlandes; ID: 199/ 09). From January 1, 2010, to March 31, 2011, all patients scheduled for 


\section{Abbreviations and Acronyms \\ $\mathrm{CABG}=$ coronary artery bypass graft \\ IABP $=$ intra-aortic balloon pump \\ NOMI $=$ nonocclusive mesenteric ischemia}

cardiac surgery at our institution were screened for participation in this trial. The inclusion criterion was elective cardiac surgery with cardiopulmonary bypass. Exclusion criteria were age $<18$ years, refusal to participate, planned off-pump surgery, urgent cardiac surgery, hemodynamic instability with emergency indication for cardiac surgery, or insufficient knowledge of the German language. Written informed consent was obtained from all patients meeting the above-mentioned criteria. The patients' demographic and perioperative data were entered in a computerized data bank in addition to the medical record chart (see Appendix 1).

\section{Radiographic Analysis}

If NOMI was suspected arterial angiography was performed. The decision to perform angiography was based on the presence of at least 2 of 4 possible clinical indicators: new onset of oliguria (urine output $<0.5 \mathrm{~mL} /$ $\mathrm{kg}$ /hour for at least 6 hours) or anuria, abdominal distention with decreased or absent bowel sounds, serum lactate levels $>5.0 \mathrm{mmol} / \mathrm{L}$ or metabolic acidosis (base excess $<-5 \mathrm{mmol} / \mathrm{L}$ ). In accordance to the definition of cardiogenic shock, ${ }^{8}$ angiography was only performed in patients with a systolic blood pressure $>90 \mathrm{~mm} \mathrm{Hg}$, and a cardiac index $>1.8 \mathrm{~L} /$ minute $/ \mathrm{m}^{2}$.

The examinations were performed on an undercouch tube/overcouch detector angiography unit (Axiom Artis, Siemens Medical Solutions, Forchheim, Germany) with a maximum field of view of $40 \mathrm{~cm}$.

In all cases the common femoral artery was accessed and a $6 \mathrm{~F}$ sheath was inserted. The superior mesenteric artery was intubated with a 4F catheter (Cordis, Johnson \& Johnson Medical Products GmbH, Vienna, Austria) with a cobra tip configuration and a digital subtraction angiography was obtained by automatic contrast medium injection (contrast medium: Imeron 300, Bracco, Milan, Italy).

All images were assessed by an experienced radiologist and an intensivist on a consensus basis. In accordance with our previously published scoring system, ${ }^{9}$ NOMI was diagnosed whenever the total score was more than 1 (Table 1).

\section{Statistics}

Data analysis was performed using SPSS Statistics version 19 (IBM, Ehningen, Germany). As a first step, patients with and without NOMI as confirmed by angiography were compared with respect to all variables assessed in this study (see Appendix 1). For categorical variables, $\chi^{2}$ tests were performed. For continuous variables the differences in manifestation (expressed as mean \pm standard deviation) between NOMI and non-NOMI patients were compared with Student $t$ tests (Welch's $t$ tests in case of inhomogeneous variance). As a second step, odds ratios were calculated for all categorical dichotomized variables (with 95\% confidence intervals) to describe the risk of developing NOMI.

Previous risk analyses only pointed toward differences between NOMI and non-NOMI patients regarding several variables. These analyses, however, did not exceed the description of the differences. Therefore, in a third step, linear discriminant analyses as well as logistic regression analyses were performed to develop a model that separates patients at high risk for developing NOMI from patients at low risk. To derive a medically sensitive predictive model, we stepwise excluded variables with low predictive values: After exclusion of the variable with the lowest predictive value, both linear discriminant and logistic regression analysis were calculated again to see how the coefficient loadings changed. Subsequently, the variable with the lowest predictive value by now was excluded, and analyses were iterated until the final equation was found. In addition, we partially reincluded several variables to compare different possible predictive models. This was done when variables had been excluded due to statistical reasons, but were previously reported to influence NOMI.

\section{RESULTS}

During the study period, 1163 adult patients underwent elective cardiac surgery with extracorporeal circulation. Because 298 patients refused participation in the study the final study population consisted of 865 individuals (74\%). Angiography was performed in 88 patients. Of these, 78 patients ( $9 \%$ of the total cohort) had the typical angiographic signs of NOMI in the absence of cardiogenic shock. Ten additional patients underwent angiography based on clinical suspicion; their findings were unremarkable. At the time of angiography systolic blood pressure was $120 \pm 15 \mathrm{~mm}$ $\mathrm{Hg}$, cardiac index was $2.7 \pm 0.3 \mathrm{~L} /$ minute $/ \mathrm{m}^{2}$, and central venous saturation was $69.1 \% \pm 1.2 \%$. Relevant outcome data are shown in Table 2.

Patients with NOMI differed in many respects from patients without NOMI (Table 3). Among preoperative parameters, renal insufficiency, diuretic therapy, and age $>70$ years showed the highest odds ratios for postoperative NOMI.

Intraoperative risk factors with clearly increased odds ratios for postoperative NOMI were duration of operation $>240$ minutes and cardiopulmonary bypass time $>100$ minutes.

The highest odds ratios for development of NOMI were observed with postoperative variables. In particular, the need for IABP support, levosimendan therapy, transfusion of $>1$ unit packed red blood cells, and re-exploration for bleeding proved to be serious risk factors. In addition, serum lactate concentrations $>5 \mathrm{mmol} / \mathrm{L}$ and norepinephrine support $>0.1 \mu \mathrm{g} / \mathrm{kg} /$ minute were associated with a clearly increased risk to develop NOMI (Table 4).

Among the calculated models, the best classification regarding medical sensitivity and practice orientation was obtained by linear discriminant analysis. The final model included 7 variables (see below; for standardized canonical coefficients see Appendix 2). The discriminant function was highly significant (Wilks' $\Lambda, 0.59 ; \chi_{7}^{2}, 449.41$; $P<.001)$. It was calculated with the following equation:

$\mathrm{d}=3.85 \times$ postoperative IABP support $(0=$ no; $1=$ yes $)$

$+1.91 \times$ re - exploration for bleeding $(0=$ no; $1=$ yes $)$

$+1.86 \times$ postoperative need for more than 1 unit PRBC $(0=$ no; $1=$ yes $)$

$+1.52 \times$ postoperative serum lactate level $>5 \mathrm{mmol} / 1$

$(0=$ no; $1=$ yes $)$ 
TABLE 1. Specific nonocclusive mesenteric ischemia (NOMI) score system ${ }^{9}$

\begin{tabular}{|c|c|c|}
\hline & Criteria/score & Description \\
\hline \multirow[t]{6}{*}{ Vessel morphhology } & 0: None & SMA trunk, branches, and mesenteric arcades normal \\
\hline & 1: Mild & $\begin{array}{l}\text { SMA trunk normal, several SMA branches and/or mesenteric arcades slightly } \\
\text { constricted }\end{array}$ \\
\hline & & SMA trunk slightly constricted, normal SMA branches and mesenteric arcades \\
\hline & & SMA trunk, several SMA branches and/or mesenteric arcades slightly constrictec \\
\hline & 2: Moderate & SMA trunk, multiple SMA branches, and/or mesenteric arcades constricted \\
\hline & 3: Severe & SMA trunk, multiple SMA branches, and/or mesenteric arcades constricted \\
\hline \multirow[t]{3}{*}{ Contrast medium reflux into the aorta } & 0: None & No contrast medium reflux into the aorta \\
\hline & 1: Mild & Some contrast medium reflux into the aorta \\
\hline & 2: Severe & Severe contrast medium reflux with complete aortogram \\
\hline \multirow[t]{3}{*}{ Contrasting of the parenchyma } & 0: Complete & Homogeneous contrasting of the intestine \\
\hline & 1: Some deficiency & Inhomogeneous contrasting of the intestine \\
\hline & 2: Complete deficiency & No contrasting of the intestine \\
\hline \multirow[t]{3}{*}{ Distension of the intestine } & $0:$ None & Up to 3 air containing, distended bowel loops \\
\hline & 1: Mild & $>3$ air containing, distended bowel loops \\
\hline & 2: Severe & Ubiquitary distended bowel loops \\
\hline \multirow[t]{3}{*}{ Contrasting time of portal vein } & $0:$ Normal & $<8 \mathrm{sec}$ \\
\hline & 1: Slightly delayed & $9-12 \mathrm{sec}$ \\
\hline & 2: Delayed & $>13 \mathrm{sec}$ \\
\hline \multirow[t]{4}{*}{ Total score } & No & 0 \\
\hline & Mild (Grade 1) & $1-5$ \\
\hline & Moderate (Grade 2) & $6-7$ \\
\hline & Severe (Grade 3) & $8-11$ \\
\hline
\end{tabular}

Summary of a specific NOMI score system used for image analysis with respect to vessel morphology, contrast medium reflux into the aorta, contrast enhancement and distension of the intestine, as well as the time of portal vein filling. The sum of each category results into a total score. SMA, Superior mesenteric artery.

$+1.07 \times$ postoperative levosimendan therapy

$(0=$ no; $1=$ yes $)$

$+0.77 \times$ postoperative need for norepinephrine

$>0.1 \mu \mathrm{g} / \mathrm{kg} / \mathrm{min}$

$(0=$ no; $1=$ yes $)$

$+0.36 \times$ postoperative loss of sinus rhythm

$(0=$ no; $1=$ yes $)$

-0.32 (constant of the equation)

TABLE 2. Comparison of relevant outcome data

\begin{tabular}{lccc}
\hline \multicolumn{1}{c}{ Outcome } & \multicolumn{3}{c}{ Non-NOMI } \\
& NOMI $(\mathbf{n}=\mathbf{7 8})$ & $(\mathbf{n}=\mathbf{7 8 7})$ & $\boldsymbol{P}$ value \\
\hline Mechanical ventilation (h) & $166.5 \pm 23.3$ & $22.1 \pm 2.0$ & $<.001$ \\
Renal replacement therapy (\%) & $42(53.4)$ & $17(2.2)$ & $<.001$ \\
LOS ICU (d) & $9.3 \pm 1.1$ & $1.8 \pm 0.1$ & $<.001$ \\
LOS IMC (d) & $6.1 \pm 0.7$ & $2.2 \pm 0.1$ & $<.001$ \\
LOS hospital (d) & $20.2 \pm 1.5$ & $11.8 \pm 0.2$ & $<.001$ \\
30-day mortality (\%) & $17(22.2)$ & $10(1.2)$ & $<.001$ \\
\hline
\end{tabular}

Data are expressed as $\mathrm{n}(\%)$ or mean \pm standard deviation. Boldface indicates statistically significant $P$ values. NOMI, Nonocclusive mesenteric ischemia; $L O S$, length of stay; $I C U$, intensive care unit; $I M C$, intermediate care unit.
The discrimination value was 1.18 ; individuals scoring higher were suspected to experience NOMI. With our model we could account for $40.7 \%$ of the variance.

In total, $92.3 \%$ of patients were correctly classified as patients with or without NOMI (Table 5). The rate of correct prediction was $76.9 \%$ for patients with NOMI (sensitivity), and $93.8 \%$ for patients without NOMI (specificity).

A parallel logistic regression model with the same independent variables as used in the prior model could account for $50.1 \%$ of variance (Nagelkerke $R^{2}, 0.50$; model $\left.\chi^{2}, 223.26 ; P<.001\right)$ and allowed for $93.9 \%$ correct predictions (Table 5). The regression model was inferior in terms of sensitivity $(43.6 \%)$ but superior in specificity $(98.9 \%)$ to the model derived from linear discriminant analyses. Importantly, 44 patients with NOMI had been mistakenly classified as asymptomatic using the regression equation, whereas the same applied for only 18 patients using the equation obtained through discriminant analyses.

\section{DISCUSSION}

A life-threatening complication of cardiac surgical procedures is intestinal ischemia. ${ }^{3,4}$ The pathomechanism of NOMI is not well understood. It is known that ileum and distal jejunum are most severely affected. ${ }^{7}$ It is as yet unclear if NOMI is simply the delayed result of 
TABLE 3. Summary of statistically significant differences between patients with and without nonocclusive mesenteric ischemia (NOMI)

\begin{tabular}{|c|c|c|c|c|}
\hline & Risk factor & $\operatorname{NOMI}(\mathbf{n}=78)$ & Non-NOMI $(\mathbf{n}=787)$ & $P$ value \\
\hline \multirow[t]{3}{*}{ Demographics } & Age (y) & $72.0 \pm 1.0$ & $62.8 \pm 0.5$ & $<.001$ \\
\hline & Height $(\mathrm{cm})$ & $169.0 \pm 1.1$ & $172.3 \pm 0.3$ & .002 \\
\hline & EuroSCORE & $8.6 \pm 0.4$ & $5.8 \pm 0.1$ & $<.001$ \\
\hline \multirow[t]{6}{*}{ Comorbidity } & Atrial fibrillation $(\%)$ & $20(26)$ & $115(14)$ & .009 \\
\hline & Coronary artery disease $(\%)$ & $48(62)$ & $325(41)$ & $<.001$ \\
\hline & Pulmonary hypertension $(\%)$ & $31(40)$ & $174(22)$ & $<.001$ \\
\hline & Chronic obstructive pulmonary disease $(\%)$ & $11(14)$ & $53(7)$ & .02 \\
\hline & Renal insufficiency $(\%)$ & $15(19)$ & $48(6)$ & $<.001$ \\
\hline & Status past stroke $(\%)$ & $7(9)$ & $28(4)$ & .02 \\
\hline \multirow[t]{3}{*}{ Medication } & Diuretic $(\%)$ & $58(74)$ & $346(44)$ & $<.001$ \\
\hline & Phenprocoumon $(\%)$ & $13(17)$ & $68(9)$ & .02 \\
\hline & Statin $(\%)$ & $34(44)$ & $232(30)$ & .01 \\
\hline \multirow[t]{4}{*}{ Intraoperative } & Coronary artery bypass grafting operations & $42(54)$ & $285(36)$ & .002 \\
\hline & Operation time (min) & $215.6 \pm 8.4$ & $166.7 \pm 1.9$ & $<.001$ \\
\hline & Cardiopulmonary bypass time (min) & $114.0 \pm 6.4$ & $82.8 \pm 1.2$ & $<.001$ \\
\hline & Crossclamp time (min) & $71.6 \pm 4.3$ & $54.4 \pm 0.8$ & $<.001$ \\
\hline \multirow[t]{13}{*}{ Postoperative } & Intra-aortic balloon pump support (\%) & $13(17)$ & $1(0.1)$ & $<.001$ \\
\hline & Sinus rhythm (\%) & $14(18)$ & $365(46)$ & $<.001$ \\
\hline & Blood loss (ml) & $1116.1 \pm 96.7$ & $622.2 \pm 17.5$ & $<.001$ \\
\hline & Re-exploration for bleeding (\%) & $18(23)$ & $13(2)$ & $<.001$ \\
\hline & Packed red blood cells (n) & $3.1 \pm 0.2$ & $1.7 \pm 0.1$ & $<.001$ \\
\hline & Levosimendan therapy $(\%)$ & $7(9)$ & $4(0.5)$ & $<.001$ \\
\hline & Norepinephrine ( $\mu \mathrm{g} / \mathrm{kg} / \mathrm{min})$ & $0.26 \pm 0.03$ & $0.06 \pm 0.01$ & $<.001$ \\
\hline & Serum lactate $>10 \mathrm{mmol} / \mathrm{L}$ & $11(14)$ & $2(0.3)$ & $<.001$ \\
\hline & Serum lactate $>5 \mathrm{mmol} / \mathrm{L}$ & $28(36)$ & $29(4)$ & $<.001$ \\
\hline & Base excess $<-5$ & $39(50)$ & $124(16)$ & $<.001$ \\
\hline & $\mathrm{pH}<7.2$ & $2(3)$ & $6(0.8)$ & $<.001$ \\
\hline & Urine output within first $24 \mathrm{~h}(\mathrm{~mL})$ & $2151 \pm 163$ & $2698 \pm 59$ & .002 \\
\hline & Urine output within first $24 \mathrm{~h}(\mathrm{~mL} / \mathrm{kg} / \mathrm{h})$ & $1.13 \pm 0.08$ & $1.41 \pm 0.03$ & .002 \\
\hline
\end{tabular}

Data are expressed as $\mathrm{n}(\%)$ or mean \pm standard deviation. Boldface indicates statistically significant $P$ values. EuroSCORE, European System for Cardiac Operative Risk Evaluation.

microcirculatory alterations initiated during cardiopulmonary bypass (CPB) or rather the manifestation of a separate disease. Several studies have also documented alterations in intestinal microcirculation during CPB. ${ }^{10-13}$ Impaired intestinal blood flow may result in breakdown of the intestinal barrier, ${ }^{14}$ which contributes to further aggravation of the physiologic alterations after CPB. Alternatively, it may be assumed that the changes in the microcirculation are a consequence of the vasopressor treatment that is necessary in many patients during and after operations involving CPB. ${ }^{15}$

NOMI is a difficult clinical problem due to the nonspecific nature of the symptoms and difficulty in diagnosis. Early identification of patients at highest risk will allow lowering the threshold for angiography as the essential diagnostic and therapeutic tool. Therefore, we initiated this prospective study to identify isolated risk factors and patients at risk for NOMI.

Previous studies have identified advanced age, severe heart failure, cardiogenic shock, chronic renal failure, and diuretic medication as important preoperative risk factors for the development of mesenteric ischemia. ${ }^{7,16}$ Among these, advanced age ( $>70$ years), chronic renal failure, and diuretic medication increases the odds ratio to develop NOMI in our study between 3- and 4-fold. These risk factors alone do not provide conclusive evidence, but may be indicative for the susceptibility of patients to development NOMI.

The most prominent postoperative factors described in the literature are hypovolemic shock, cardiogenic shock, administration of $\alpha$-adrenergic drugs, or the use of an IABP. ${ }^{7,16}$ In line with these findings, extended norepinephrine use, levosimendan therapy, or postoperative IABP support increases the odds ratio to develop NOMI in our study between 18- and 153-fold.

Vasopressor treatment is necessary in many patients during and after operations involving CPB. ${ }^{17-19}$ In this context, treatment with $\alpha$-adrenergic catecholamines like norepinephrine may lead to an increased incidence of NOMI after CPB. ${ }^{12}$ It may be assumed that these changes in the microcirculation are a consequence of a hypercontractile response of ileal microvessels after $\alpha$-adrenoceptor stimulation. ${ }^{12,15,17}$ In addition, norepinephrine simulates in a dose-dependent manner $\beta$ receptors, which has been shown to increase intestinal oxygen consumption. ${ }^{20}$ 
TABLE 4. Odds ratios of perioperative risk factors

\begin{tabular}{|c|c|c|c|c|}
\hline & Risk factor & $\begin{array}{l}\text { Odds } \\
\text { ratio }\end{array}$ & $\mathbf{9 5} \% \mathrm{CI}$ & $\begin{array}{c}P \\
\text { value }\end{array}$ \\
\hline \multirow[t]{4}{*}{ Demographics } & Age $>70 y$ & 2.82 & $1.74-4.60$ & $<.001$ \\
\hline & Height $>170 \mathrm{~cm}$ & 0.51 & $0.32-0.82$ & $<.05$ \\
\hline & EuroSCORE $>7$ & 2.33 & $1.65-4.01$ & $<.001$ \\
\hline & Atrial fibrillation & 2.17 & $1.27-3.73$ & $<.001$ \\
\hline \multirow[t]{5}{*}{ Comorbidity } & Coronary artery disease & 2.03 & $1.31-3.32$ & $<.05$ \\
\hline & Pulmonary hypertension & 2.48 & $1.53-4.01$ & $<.001$ \\
\hline & $\begin{array}{l}\text { Chronic obstructive } \\
\text { pulmonary disease }\end{array}$ & 2.46 & $1.22-4.95$ & $<.001$ \\
\hline & Renal insufficiency & 3.95 & $2.12-7.37$ & $<.001$ \\
\hline & Status past stroke & 2.60 & $1.10-6.16$ & $<.001$ \\
\hline \multirow[t]{3}{*}{ Medication } & Diuretics & 3.79 & $2.24-6.43$ & $<.001$ \\
\hline & Phenprocoumon & 2.12 & $1.11-4.03$ & $<.05$ \\
\hline & Statins & 1.85 & $1.15-2.97$ & $<.05$ \\
\hline \multirow[t]{5}{*}{ Intraoperative } & $\begin{array}{c}\text { Coronary artery bypass } \\
\text { grafting operations }\end{array}$ & 2.01 & $1.29-3.28$ & $<.05$ \\
\hline & Operation time $>240 \mathrm{~min}$ & 5.62 & $3.26-9.69$ & $<.001$ \\
\hline & Operation time $>180 \mathrm{~min}$ & 3.28 & $2.02-5.31$ & $<.001$ \\
\hline & $\begin{array}{l}\text { Cardiopulmonary bypass } \\
\text { time }>100 \mathrm{~min}\end{array}$ & 3.83 & $2.38-6.17$ & $<.001$ \\
\hline & Crossclamp time $>60$ min & 2.19 & $1.37-3.49$ & $<.05$ \\
\hline \multirow[t]{14}{*}{ Postoperative } & $\begin{array}{l}\text { Intra-aortic balloon pump } \\
\text { support }\end{array}$ & 153.00 & $19.70-1188.08$ & $<.001$ \\
\hline & Loss of sinus rhythm & 3.53 & $2.00-6.22$ & $<.001$ \\
\hline & Blood loss $>1000 \mathrm{ml}$ & 7.22 & $4.29-12.14$ & $<.001$ \\
\hline & Re-exploration for bleeding & 24.22 & $11.64-59.42$ & $<.001$ \\
\hline & Packed red blood cells $>2$ & 20.05 & $11.39-35.27$ & $<.001$ \\
\hline & Packed red blood cells $>1$ & 12.77 & $7.66-21.27$ & $<.001$ \\
\hline & Levosimendan therapy & 18.78 & $5.37-65.71$ & $<.001$ \\
\hline & $\begin{array}{l}\text { Norepinephrine } \\
\quad>0.2 \mu \mathrm{g} / \mathrm{kg} / \mathrm{min}\end{array}$ & 17.47 & $9.01-33.88$ & $<.001$ \\
\hline & $\begin{array}{l}\text { Norepinephrine } \\
\quad>0.1 \mu \mathrm{g} / \mathrm{kg} / \mathrm{min}\end{array}$ & 12.14 & $7.18-20.52$ & $<.001$ \\
\hline & Serum lactate $>10 \mathrm{mmol} / \mathrm{L}$ & 139.09 & $17.81-1086.33$ & $<.001$ \\
\hline & Serum lactate $>5 \mathrm{mmol} / \mathrm{L}$ & 15.60 & $8.61-28.26$ & $<.001$ \\
\hline & Base excess $<-5$ & 5.50 & $3.39-8.93$ & $<.001$ \\
\hline & $\mathrm{pH}<7.2$ & 3.33 & $0.66-16.80$ & $<.001$ \\
\hline & $\begin{array}{l}\text { Oliguria/anuria within the } \\
\text { first } 24 \mathrm{~h}\end{array}$ & 2.17 & $1.22-3.65$ & $<.001$ \\
\hline
\end{tabular}

Data are expressed as odds ratio for each recorded categorical respectively dichotomized variable and $95 \%$ confidence interval (CI). Boldface indicates statistically significant $P$ values. EuroSCORE, European System for Cardiac Operative Risk Evaluation

Irrespective of the surgical procedure, patients after cardiac surgery are still vulnerable to low cardiac output syndrome or cardiogenic shock. Pharmacologic interventions are commonly limited to catecholamines, phosphodiesterase III inhibitors, and levosimendan, which has recently received more attention. ${ }^{21}$ Due to the cost of levosimendan it is usually restricted to refractory cardiogenic shock. Although levosimendan therapy is well tolerated, most of its adverse effects are due to its vasodilating effect. ${ }^{21}$ This side effect itself and/or the resulting need for increased vasopressor treatment may additionally aggravate intestinal
TABLE 5. Comparison between linear discriminant and logistic regression analysis to predict nonocclusive mesenteric ischemia (NOMI)

\begin{tabular}{lccccc}
\hline & \multicolumn{3}{c}{ Predicted diagnosis } \\
\cline { 2 - 3 } \multicolumn{1}{c}{$\begin{array}{c}\text { Clinical } \\
\text { diagnosis }\end{array}$} & $\begin{array}{c}\text { Lonear discriminant } \\
\text { analysis }\end{array}$ & & \multicolumn{2}{c}{$\begin{array}{c}\text { Logistic regression } \\
\text { analysis }\end{array}$} \\
\cline { 2 - 3 } \cline { 5 - 6 } non-NOMI & $\mathbf{7 3 8 ( 9 3 . 8 )}$ & $49(6.2)$ & & $\mathbf{7 7 8}(\mathbf{9 8 . 9})$ & $9(1.1)$ \\
NOMI & $18(23.1)$ & $\mathbf{6 0}(\mathbf{7 6 . 9})$ & & $44(56.4)$ & $\mathbf{3 4}(\mathbf{4 3 . 6})$ \\
\hline
\end{tabular}

Data are presented as n (\%). Boldface indicates correct predictions. Linear discriminant analysis classified $92.3 \%$ of all patients correctly, whereas logistic regression analysis showed a correct prediction rate of $93.9 \%(n=865)$.

hypoperfusion. Nevertheless, we do not think that levosimendan itself is a risk factor for the development of NOMI, but its need in the treatment of cardiogenic shock seems to be a clue for impaired intestinal perfusion.

IABP implantation after cardiac surgery is a commonly used form of circulatory support for patients with postoperative low cardiac output syndrome. Despite improving coronary perfusion and reducing left ventricular afterload, IABP use is known as risk factor for the development of lethal mesenteric ischemia. ${ }^{22}$ One explanation for this unwanted side effect is the malposition of the IABP balloon, resulting in compromised visceral blood flow. This hypothesis is supported by Rastan and colleagues ${ }^{23}$ who found a malposition of the IABP balloon with consecutive visceral artery compromise in up to $97 \%$ of their study patients. After insertion of the IABP, the position was immediately confirmed by chest $\mathrm{x}$-ray film. At angiography we only found 3 patients $(23 \%)$ with a malposition of the IABP balloon, which was then corrected. Therefore, an incorrect-positioned IABP balloon may aggravate a state of intestinal hypoperfusion, but does not explain alone the $>150$-fold odds increase for the development of NOMI in our patients. Moreover, NOMI was confirmed after restoration of an adequate hemodynamic, underlining that NOMI is a distinct complication after cardiogenic shock. Therefore, despite an apparently re-established stable hemodynamic situation, NOMI should be kept in mind as a life-threatening complication.

Intestinal ischemia may lead to a systemic inflammatory response syndrome and sepsis thereby altering the coagulation system in both ways, hyper- and hypocoagulation. ${ }^{24}$ Bleeding is additionally known to be a strong proinflammatory stimulus, which further aggravates systemic inflammatory response syndrome and sepsis. ${ }^{24}$ A circulus vitiosus that ends up in distinct NOMI may be the result. This is supported by higher odds ratios to develop NOMI in patients with increased blood loss, need for $>1$ unit packed red blood cells, or need for chest re-exploration. In 15 of 18 patients, however, no surgical source of bleeding was found while re-exploring the chest, suggesting coagulopathy caused by NOMI.

Elevated serum lactate levels, metabolic acidosis, and increased serum creatinine kinase levels have been described 
in previous studies to be indicative but not providing conclusive evidence for NOMI. ${ }^{4}$ We found significantly higher serum lactate levels in patients with NOMI compared with patients without. Furthermore, patients with serum lactate levels of $>5 \mathrm{mmol} / \mathrm{L}$ had an increased odds ratio of 15.60 to show the angiographic signs of NOMI. This may be due to an increased intestinal lactate production as a result of anaerobic glycolysis. It is, however, impossible to discriminate between lactate production due to systemic or local hypoperfusion.

All these postoperative predictors have to be looked at in the context of preoperative morbidity and intraoperative events. Especially intraoperative physiology is difficult or impossible to define clearly; myocardial protection, suboptimal correction of cardiovascular pathology, and hemodynamic derangement cannot be quantified in clinical practice and may have effects that extend into postoperative treatment.

Despite the possibility to detect intestinal malperfusion by contrast multidetector row computed tomography, ${ }^{25}$ catheter angiography remains the gold standard for the early diagnosis of NOMI. In addition to the direct visualization of the mesenteric blood flow, the inserted catheter allows selective mesenteric intra-arterial infusion of vasodilatative drugs. Early recognition and correction of the vascular pathology is the only way to reduce the high morbidity and mortality of NOMI. ${ }^{7}$ Nevertheless, angiography is an invasive procedure that cannot be applied too liberally due to its potential side effects. To alleviate the decision process to perform angiography, we tried to identify patients who are at risk to develop NOMI by using a discriminant and regression approach, respectively. The final risk equation showed a good sensitivity and high specificity. Using this equation, we were able to exclude NOMI in $>90 \%$ of cases. As a result the sensitivity was only $76 \%$; this reflects our key intention to aim for a high specificity. In our mind the high mortality of untreated NOMI warrants a test that has the lowest possible false negative rate.

Linear discriminant analysis may be discussed controversially because this method is meant for the analysis of continuous independent variables. The use of supplemental categorical variables, in the form of dummy variables, is allowed. In our predictive model all continuous variables had to be eliminated because they showed no explanatory value. Because discriminant analysis is not designated for exclusively dichotomous data, our equation model may be problematic for statistical reasons. From a clinical perspective, the results obtained through linear discriminant analysis are superior to the results obtained through logistic regression analysis. In the first case, the predictive model had a false negative rate of $23.1 \%(n=18$ [ $2.1 \%$ of the total cohort]), whereas the predictive model derived from logistic regression analysis had a rate of $56.4 \%(n=44[5.1 \%$ of the total cohort]). Because false negative NOMI predictions are associated with high mortality rates, type II error is much more important than sensitivity rate.

Another limitation of our study is that our control group (non-NOMI patients) did not undergo angiography. Therefore we cannot exclude that patients with clinical unapparent forms of NOMI were missed. The mortality in our control group was low $(1.2 \%)$; in addition, none of these patients died within the first 10 postoperative days. These facts and the clinical course of the patients makes NOMI very unlikely.

Emergency operations are associated with a higher incidence of NOMI. ${ }^{26}$ Due to the study design we excluded all urgent and emergency operations. Therefore, we cannot comment on whether or not these patients are at higher risk for the development of NOMI. Nevertheless, our risk equation consists of pre- and postoperative variables, which helps to easily identify risk patients independent of the operation indication.

\section{CONCLUSIONS}

Our study provides for the first time prospective observational data on risk factors for the development of NOMI in patients undergoing elective cardiac surgery. Summarizing our results, a high index of suspicion for NOMI in patients with the above-mentioned risk factors may decrease the diagnostic delay. This may lead to a decreased mortality due to earlier intervention. To better identify risk patients the developed risk equation is a useful tool with a high specificity and low type II error rate.

The authors thank Timo Speer for his support in database maintenance.

\section{References}

1. Ende N. Infarction of the bowel in cardiac failure. N Engl J Med. 1958;258: 879-81.

2. Haglund U, Hulten L, Ahren C, Lundgren O. Mucosal lesions in the human small intestine in shock. Gut. 1975;16:979-84.

3. Klotz S, Vestring T, Rotker J, Schmidt C, Scheld HH, Schmid C. Diagnosis and treatment of nonocclusive mesenteric ischemia after open heart surgery. Ann Thorac Surg. 2001;72:1583-6.

4. Abboud B, Daher R, Boujaoude J. Acute mesenteric ischemia after cardiopulmonary bypass surgery. World J Gastroenterol. 2008;14:5361-70.

5. Howard TJ, Plaskon LA, Wiebke EA, Wilcox MG, Madura JA. Nonocclusive mesenteric ischemia remains a diagnostic dilemma. Am J Surg. 1996;171:405-8.

6. Bassiouny HS. Nonocclusive mesenteric ischemia. Surg Clin North Am. 1997; 77:319-26.

7. Trompeter M, Brazda T, Remy CT, Vestring T, Reimer P. Non-occlusive mesenteric ischemia: etiology, diagnosis, and interventional therapy. Eur Radiol. 2002; 12:1179-87.

8. Van de Werf F, Bax J, Betriu A, Blomstrom-Lundqvist C, Crea F, Falk V, et al. Management of acute myocardial infarction in patients presenting with persistent ST-segment elevation: the Task Force on the Management of ST-Segment Elevation Acute Myocardial Infarction of the European Society of Cardiology. Eur Heart J. 2008;29:2909-45.

9. Minko P, Groesdonk H, Stroeder J, Miodek J, Graeber S, Bucker A, et al. A scoring system for the assessment of angiographic findings in non-occlusive mesenteric ischemia (NOMI). Rofo. 2012;184:805-9.

10. Tao W, Zwischenberger JB, Nguyen TT, Vertrees RA, McDaniel LB, Nutt LK, et al. Gut mucosal ischemia during normothermic cardiopulmonary bypass 
results from blood flow redistribution and increased oxygen demand. $J$ Thorac Cardiovasc Surg. 1995;110:819-28.

11. Doguet F, Litzler PY, Tamion F, Richard V, Hellot MF, Thuillez C, et al. Changes in mesenteric vascular reactivity and inflammatory response after cardiopulmonary bypass in a rat model. Ann Thorac Surg. 2004;77:2130-7; author reply 2137.

12. O'Dwyer C, Woodson LC, Conroy BP, Lin CY, Deyo DJ, Uchida T, et al. Regional perfusion abnormalities with phenylephrine during normothermic bypass. Ann Thorac Surg. 1997;63:728-35.

13. Bomberg H, Bierbach B, Flache S, Wagner I, Glaser L, Groesdonk HV, et al. Endothelin and vasopressin influence splanchnic blood flow distribution during and after cardiopulmonary bypass. J Thorac Cardiovasc Surg. 2012 Apr 30 [Epub ahead of print].

14. Rocke DA, Gaffin SL, Wells MT, Koen Y, Brock Utine JG. Endotoxemia associated with cardiopulmonary bypass. J Thorac Cardiovasc Surg. 1987; 93:832-7.

15. Tofukuji M, Stahl GL, Metais C, Tomita M, Agah A, Bianchi C, et al. Mesenteric dysfunction after cardiopulmonary bypass: role of complement C5a. Ann Thorac Surg. 2000;69:799-807.

16. Lock G. Acute intestinal ischaemia. Best Prac Res Clin Gastroenterol. 2001;15: 83-98.

17. Khan TA, Bianchi C, Ruel M, Feng J, Sellke FW. Differential effects on the mesenteric microcirculatory response to vasopressin and phenylephrine after cardiopulmonary bypass. J Thorac Cardiovasc Surg. 2007;133:682-8.

18. Argenziano M, Chen JM, Choudhri AF, Cullinane S, Garfein E, Weinberg AD, et al. Management of vasodilatory shock after cardiac surgery: identification of predisposing factors and use of a novel pressor agent. $J$ Thorac Cardiovasc Surg. 1998;116:973-80

19. Morales DL, Gregg D, Helman DN, Williams MR, Naka Y, Landry DW, et al Arginine vasopressin in the treatment of 50 patients with postcardiotomy vasodilatory shock. Ann Thorac Surg. 2000;69:102-6.

20. Salak N, Pajk W, Knotzer H, Hofstotter H, Schwarz B, Mayr A, et al. Effects of epinephrine on intestinal oxygen supply and mucosal tissue oxygen tension in pigs. Crit Care Med. 2001;29:367-73.

21. Mebazaa A, Pitsis AA, Rudiger A, Toller W, Longrois D, Ricksten SE, et al. Clinical review: practical recommendations on the management of perioperative heart failure in cardiac surgery. Crit Care. 2010;14:201.

22. Venkateswaran RV, Charman SC, Goddard M, Large SR. Lethal mesenteric ischaemia after cardiopulmonary bypass: a common complication? Eur J Cardiothorac Surg. 2002;22:534-8

23. Rastan AJ, Tillmann E, Subramanian S, Lehmkuhl L, Funkat AK, Leontyev S, et al. Visceral arterial compromise during intra-aortic balloon counterpulsation therapy. Circulation. 2010;122(11 suppl):S92-9.

24. van der Poll T, de Boer JD, Levi M. The effect of inflammation on coagulation and vice versa. Curr Opin Infect Dis. 2011;24:273-8.

25. Mitsuyoshi A, Obama K, Shinkura N, Ito T, Zaima M. Survival in nonocclusive mesenteric ischemia: early diagnosis by multidetector row computed tomography and early treatment with continuous intravenous high-dose prostaglandin E(1). Ann Surg. 2007;246:229-35.

26. Allen KB, Salam AA, Lumsden AB. Acute mesenteric ischemia after cardiopulmonary bypass. J Vasc Surg. 1992;16:391-5; discussion 395-6.

APPENDIX 1. Summary of all documented data analyzed in this study

\begin{tabular}{|c|c|c|}
\hline & Data & Description \\
\hline \multirow[t]{14}{*}{ Demographics } & Sex & \\
\hline & Girls & Sex of each patient \\
\hline & Boys & Sex of each patient \\
\hline & Age & Age, documented in years $(y)$ \\
\hline & Weight & Body weight, documented in kilograms \\
\hline & Size & Size, documented in centimeters \\
\hline & EuroSCORE & EuroSCORE, documented in absolute value \\
\hline & Ejection fraction & Ejection fraction, documented in percent $(\%)$ \\
\hline & New York Heart Association functional class & New York Heart Association functional class, documented in absolute value \\
\hline & Sinus rhythm & Documented sinus rhythm at the day of admission to the hospital \\
\hline & Arterial hypertension & Systolic arterial pressure $>140 \mathrm{~mm} \mathrm{Hg}$ and/or diastolic arterial pressure $>90 \mathrm{~mm} \mathrm{Hg}$ \\
\hline & Karnofsky Index & Karnofsky Index, documented in absolute value \\
\hline & Smoker & Active smoker at the day of admission to the hospital \\
\hline & Pack years & No. of pack years $=$ packs smoked $/ \mathrm{d} \times$ years as a smoker \\
\hline \multirow[t]{9}{*}{ Comorbidity } & Coronary artery disease & Confirmed by cardiac catheter examination \\
\hline & Vitium & All kinds of valvular disease with indication for surgery \\
\hline & Chronic pulmonary thromboembolism & Confirmed by angiography \\
\hline & Pulmonary hypertension & Mean pulmonary artery pressure $>25 \mathrm{~mm} \mathrm{Hg}$ at rest or $>30 \mathrm{~mm} \mathrm{Hg}$ with exercise \\
\hline & Chronic obstructive pulmonary disease & Global Initiative for Chronic Obstructive Lung Disease $\geq 2$ \\
\hline & Renal insufficiency & Effective glomerular filtration rate $<60 \mathrm{~mL} / \mathrm{min}$ \\
\hline & Hemodialysis & Terminal renal failure with the need for dialysis \\
\hline & Malignacy & All kinds of malignant disease \\
\hline & Status past stroke & Status past stroke with or without residua \\
\hline \multirow[t]{9}{*}{ Medication } & Beta blocker & All kinds of beta blocker therapy for at least $4 \mathrm{wk}$ before operation \\
\hline & ACE inhibitor & All kinds of ACE inhibitor therapy for at least $4 \mathrm{wk}$ before operation \\
\hline & AT-1 blocker & All kinds of AT-1 blocker therapy for at least $4 \mathrm{wk}$ before operation \\
\hline & Calcium antagonist & All kinds of calcium antagonist therapy for at least $4 \mathrm{wk}$ before operation \\
\hline & Diuretic & All kinds of diuretic therapy for at least $4 \mathrm{wk}$ before operation \\
\hline & Acetylsalicylic acid & All kinds of acetylsalicylic acid therapy for at least $4 \mathrm{wk}$ before operation \\
\hline & Phenprocoumon & All kinds of phenprocoumon therapy for at least $4 \mathrm{wk}$ before operation \\
\hline & Amiodarone & All kinds of amiodarone therapy for at least $4 \mathrm{wk}$ before operation \\
\hline & Statin & All kinds of statin therapy for at least 4 wk before operation \\
\hline
\end{tabular}




\begin{tabular}{|c|c|c|}
\hline & Data & Description \\
\hline \multirow[t]{10}{*}{ Intraoperative } & Procedure type & \\
\hline & CABG operations & All kinds of coronary artery bypass surgery with cardiopulmonary bypass \\
\hline & Valve operations & All kinds of valve surgery with cardiopulmonary bypass \\
\hline & Pulmonary thromboendarterectomy & Pulmonary thromboendarterectomy \\
\hline & Combination surgery & All kinds of combination surgery with cardiopulmonary bypass \\
\hline & Redo CABG and/or valve & All kinds of redo surgery with cardiopulmonary bypass \\
\hline & Operation time & Operation time, documented in minutes \\
\hline & $\mathrm{CPB}$ time & Cardiopulmonary bypass time, documented in minutes \\
\hline & Crossclamp time & Aortic crossclamp time, documented in minutes \\
\hline & HCA time & HCA time, documented in minutes \\
\hline \multirow[t]{12}{*}{ Postoperative } & IABP support & Postoperative need for IABP support \\
\hline & Loss of sinus rhythm & Documented loss of sinus rhythm for at least $6 \mathrm{~h}$ \\
\hline & Blood loss & Blood loss, documented in milliliters \\
\hline & Re-exploration for bleeding & Need for re-exploration of the chest due to bleeding \\
\hline & Packed red blood cells & No. of packed red blood cells \\
\hline & Levosimendan therapy & Postoperative need for levosimendan therapy \\
\hline & Norepinephrine therapy & $\begin{array}{l}\text { Postoperative need for norepinephrine therapy, documented in micrograms/kilogram/ } \\
\text { minute }\end{array}$ \\
\hline & Serum lactate & Postoperative serum lactate levels \\
\hline & Base excess & Postoperative base excess values \\
\hline & $\mathrm{pH}$ value & Postoperative $\mathrm{pH}$ values \\
\hline & Urine output within first $24 \mathrm{~h}$ & Postoperative urine output, documented in milliliters \\
\hline & Urine output within first $24 \mathrm{~h}(\mathrm{ml} / \mathrm{kg} / \mathrm{h})$ & Postoperative urine output, documented in milliliters/kilogram/hour \\
\hline \multirow[t]{6}{*}{ Outcome } & Mechanical ventilation & Time of postoperative mechanical ventilation, documented in hours \\
\hline & Renal replacement therapy & Need for renal replacement therapy due to new onset of acute kidney injury \\
\hline & LOS ICU & LOS in the ICU, documented in days \\
\hline & LOS IMC & LOS in the IMC unit, documented in days \\
\hline & LOS hospital & LOS in the hospital, documented in days \\
\hline & 30-d mortality & 30-d mortality including all causes of death \\
\hline
\end{tabular}

In total 52 isolated risk factors where included in our risk stratification calculations. $A C E$, Angiotensin-converting enzyme; $A T-1$, angiontensin-1; $C A B G$, coronary artery bypass grafting; $C P B$, cardiopulmonary bypass; $H C A$, hypothermic circulatory arrest; $I A B P$, intra-aortic balloon pump; $L O S$, length of stay; $I C U$, intensive care unit; $I M C$, intermediate care unit; EuroSCORE, European System for Cardiac Operative Risk Evaluation.

APPENDIX 2. Summary of stepwise discriminant analysis

\begin{tabular}{lc}
\hline \multicolumn{1}{c}{ Predictor } & $\begin{array}{c}\text { Standardized } \\
\text { coefficient loadings }\end{array}$ \\
\hline Postoperative IABP support & 0.451 \\
Re-exploration for bleeding & 0.348 \\
Postoperative need for more than $2 \mathrm{PRBC}$ & 0.456 \\
Postoperative serum lactate level $>5 \mathrm{mmol} / \mathrm{L}$ & 0.351 \\
Postoperative need for norepinephrine & 0.221 \\
$\quad>0.1 \mu \mathrm{g} / \mathrm{kg} /$ min & \\
Postoperative levosimendan therapy & 0.117 \\
Postoperative loss of sinus rhythm & 0.179 \\
Canonical correlation & 0.638 \\
Eigenvalue & 0.687 \\
Wilks' lambda & 0.593 \\
$\chi^{2}$ & $449.41(d f=7 ; P<.001)$ \\
IABP, Intra-aortic balloon pump; $P B R C$, packed red blood cells; $d f$, degrees of \\
freedom.
\end{tabular}

